\title{
Effects of Manual, Cultural, Botanical and Chemical Treatments of Termite Control in Hamelmalo Agricultural College Area
}

\author{
Biniam Efriem, Habteab Goitom, Rayet Idris, Yosief Girmay, Adungna Haile \\ Department of Plant Protection, Hamelmalo Agricultural College, Keren, Eritrea \\ Email: kibromhabtish23@gmail.com
}

How to cite this paper: Efriem, B., Goitom, H., Idris, R., Girmay, Y. and Haile, A. (2021) Effects of Manual, Cultural, Botanical and Chemical Treatments of Termite Control in Hamelmalo Agricultural College Area. Open Journal of Ecology, 11, 64-74. https://doi.org/10.4236/oje.2021.111006

Received: November 30, 2020

Accepted: January 11, 2021

Published: January 14, 2021

Copyright $\odot 2021$ by author(s) and Scientific Research Publishing Inc. This work is licensed under the Creative Commons Attribution International License (CC BY 4.0).

http://creativecommons.org/licenses/by/4.0/

\begin{abstract}
Termites are the most serious pests of field and horticultural crops, forests, and wooden household furniture. In Hamelmalo Agricultural College (HAC) the infestation of termite is very high resulting in great destruction of crop plants and wooden office and dormitory furniture. The devastating attack of termites should be managed by using best and ecofriendly management method. The purpose of the study was to compare the effectiveness of manual destruction of mounds and killing of termite queen and king, chemical chlorpyrifos, seed and leaves extract of neem and Lantana (as separate experiment) and smoke on termite control. Termite mounds were selected randomly inside HAC compound. The materials used were hand hoe, spade, fork, water, $20 \mathrm{~L}$ jar and protective clothes. The treatments were replicated three times. The botanical treatments were prepared at $2 \mathrm{~L}$ of highly concentrated extracts per $20 \mathrm{~L}$ of water each. Chlorpyrifos was applied at $20 \mathrm{ml}$ per $20 \mathrm{~L}$ of water. Dried woody plants were used for smoke treatment. Careful digging was done to avoid king escape and queen rupture and they were killed by burning. Among all, the mechanical destruction and killing of king and queen and chlorpyrifos resulted in a complete control of the termite population. Except in the mounds treated by chlorpyrifos, the activity of termite population was very active and they closed the opened galleries immediately after treatment even though there were dead termite castes in all treatments. Living termite castes were counted by taking a medium size spade of broken mound pieces. The highest count was recorded from mounds treated by smoke. After two weeks the queen and king in every treatment mound were cheeked and killed for those who were alive. Except by the chlorpyrifos and manual destruction of mound (king and queen were killed before) all the royal families were alive and killed. Controlling of termite population in the field (outside their mound) is not possible due to the hid-
\end{abstract}


den foraging activity of termites, environmental safety from chemicals and the high egg laying potential of the queen. Finding the best alternative to control from their source mound for the mound building termites resulted in effective control of the population by manual destruction of mounds and killing of queen and king and chlorpyrifos. By the side effect of chlorpyrifos to untargeted organisms and the time consuming and laborious method of manual destruction of mounds, selection to the best from these two control measure is almost the same.

\section{Keywords}

Termite Castes, Mounds, Cultural, Mechanical, Chlorpyrifos, Lantana Seed and Leaf Extract, Neem Leaf and Seed Kernel Extract

\section{Introduction}

Termites are the most important pests, as they are destructive and major threats to crops and houses infrastructures. Termites cause damages to structural timbers, household furniture, paper products, many other synthetic materials and storage food (if storage rooms/houses/storage materials are not concrete) [1] [2] [3]. They are distributed worldwide [4]. Termites have been found in all types of soils except in semi-permanently water logged areas and in certain deeply cracking vertisols [5]. Estimates of losses due to termites vary widely with the crop or material they damage. Termite infestation increases with various stress factors such as drought, prolonged dry spells and low soil fertility [4] [6] [7] [8]. Termites damage plants by boring into the roots and stems. They can attack crops both in their underground and above ground plant parts and feed on tubers, groundnut pods and seeds, roots, lower and older leaves, stems and lower branches of the plant by biting and chewing. [9] [10] [11] [12]. They can also make channels in/on the soil up to the top part of trees [13]. Plants attacked by termites fall down easily [14].

In semi-arid savannah ecosystem of Kenya, termites foraging activities are responsible for destruction of $800-1500 \mathrm{~kg} / \mathrm{ha}$ of pasture per year [15]. Similarly in South Africa, harvester termites are the serious pest of range land which are removing $60 \%$ or more of the standing grass biomass during dry years [16] [17]. Apart from damage to crops and range land, termites are commonly responsible for mortality of tree seedlings and cause considerable damage to buildings and other structures such as wooden fence and woods [18]. In agro-ecosystem, termites attack many annual and perennial crops such as sugarcane, rice, cassava, ground nut and wheat. Crops attacked by termites show significant yield loss, especially in semi-arid and semi-humid tropical areas [1] [4].

In Eritrea, even though termites attack infrastructure of house, house hold furniture, tress, orchard plants and pasture lands, the researches done to solve this problem are limited. In agriculture they cause damage to a number of crops 
such as barley, wheat, maize, sorghum, taff and pearl millet. Farmers who suffered from the damage of termites do not leave their harvested crops in contact with the soil in field. Crop lodging due to wind or other factors is completely damaged that results in yield loss. The mound building termites can also build their nests inside a house which have being a greater opportunity of damaging stored grains and other wooden household furniture. In the lowlands of Eritrea where the farmers use hut and other wooden structure houses, the house and household furniture which are made up of wood are attacked by termites. This termite attack may completely damage the properties unless precautions are done by the owners. Trees and orchards are hardly free of termites especially when the conditions are optimum for termites such as drought conditions. In addition pasture lands which are used as animal grazing are also susceptible to termites, which result in lack of animal feed.

The distribution of termites in Eritrea may vary with soil type and climate. In HAC area, having a sandy loam soil, termites cause considerable damage to campus crops starting from seedling to maturity stage. The campus had high infestation of termites that affects office furniture such as chairs, cupboards and library books especially when the school is closed and less care is done. Even though the infestation of termite is very high in the campus limited research was previously done to tackle the problems of their damage. The seriousness of termite pests is not restricted in the campus only as farmers who were part time labourer in the campus indicated there were a damage of termites in their wooden materials, stored grain and their crops in the field, especially when harvested crop left for night on the soil. The purpose of this research was to identify the most appropriate and affordable control measure so that the college and farmers may get benefited.

\section{Materials and Methods}

The study was conducted in Hamelmalo Agricultural College (HAC). HAC is located in Anseba region 12 kilometers northeast of Keren on the highway to Nakfa. The altitude of the study area is $1286 \mathrm{~m}$ above sea level and its position is $15^{\circ}$ to $53^{\circ} \mathrm{N}$ latitude and $38^{\circ}$ to $66^{\circ} \mathrm{E}$ longitudes. The area receives an average annual rainfall of $450 \mathrm{~mm}$, with temperature that varies from $16^{\circ} \mathrm{C}$ to $38^{\circ} \mathrm{C}$ during the cold period of November and December and dry season of March to June respectively with a mean temperature of $27^{\circ} \mathrm{C}$. The soil type of the study area is sandy loam and the main crops sown in that area are sorghum, pearl millet and ground nut. In addition along the bank of river Anseba farmers produce citrus and mango fruits and vegetables mainly tomato, pepper and okra.

The materials used during the study period were hand hoe for digging, spade for dumping of soil from the mounds, safety match, ax for cutting of neem and lantana plants, prism box for taking samples, and weight balance. All the materials were obtained from Department of Plant Protection. Other materials used were twigs, seeds and leaves of lantana and neem for extraction of botanical insecticide and mortar and pestle for grinding them. The experimental mounds 
were selected at random with three replications. There were five treatments that include manual/mechanical removal of the queen and king and killing them by burning, smoke of dried wood, insecticide chlorpyrifos, neem seed and lantana seed extracts. The termite living castes count was done after $24 \mathrm{hrs,} \mathrm{one} \mathrm{and} \mathrm{two}$ weeks of treatment. One spade of mound pieces from each mound was taken and the living termite colony that had taken away was counted. After the last count ( 2 weeks) the king and queen were checked.

Prior to the start of the work, all mounds that were used for each treatment was selected randomly. All the selected mounds were with active termite castes activity. The mounds under the foundations were not considered because of the difficulty to dig out. Mound size was not considered in order to reduce the error of biasness. The selected mound was dug carefully to locate and remove the queen and king from the mound. Observations on nymphs within the mounds and the density of adult activities were the clues used during the time of digging to locate the queen. The queen and king were collected and burned in order to damage all matured eggs which were not laid.

For the mounds designed for chemical treatment, $20 \mathrm{ml}$ of chlorpyrifos was mixed in $20 \mathrm{~L}$ of water and applied for each mound. The mounds were dug up to big galleries and then the chemical was applied through different directions of the mound.

To study the effectiveness of smoke on termite population and to select the best alternative of termite management, dried woods of about 0.7 - $1 \mathrm{~m}$ were cut and burned outside the mound. Those burning woods were then inserted in to the half opened mounds. The smoke that was coming out was blocked by broad leaves of grasses of that area. This application continues up to half an hour of time by adding woods and directing the smoke toward the centre of the mound.

To treat mounds with neem seed kernels and leaves extract, first the top part of the mound was dug out. Then after digging the top part of the mound, the neem seed kernels and leaves extract was applied by three big holes in different direction. Two kilogram of neem seed kernels and leaves of neem tree was grinded and soaked overnight. The next day they were extracted to $2 \mathrm{~L}$ of highly concentrated solution and diluted to $20 \mathrm{~L}$ of water which were finally applied to the treatment mounds.

To cheek the effectiveness of lantana seed and leaves extract over termite population, two kilograms of seed and leaves extract of lantana plant was grinded and soaked overnight. Then it was extracted to $2 \mathrm{~L}$ of highly concentrated solution. This solution was diluted to $20 \mathrm{~L}$ of water. After that the top part of the mound was dug out to open big openings. Finally it was applied to the mounds of treatment in different directions.

\section{Results}

Comparing the five treatments in randomly selected mounds which have replicated three times, the chlorpyrifos and manual removal of queen and king resulted in a complete control of termite colonies. Kaleab's group also reported the 
same result on the efficiency of manual and chlorpyrifos application on termite colony. Tafaban (chlorpyrifos) killed termite colony quickly by direct contact [19]. Even though large reduction of termites were observed when treated with neem seed kernels and leaves as well as lantana seed and leaves extract, but later the activities of the workers and emergence of new nymphs were observed. Similarly the reduction of termite colony was observed after smoke application but their activity was immediately resumed (Table 2). In mounds treated with chlorpyrifos and manual removal of the royal family, some of the mounds were left open while others were closed but the growth of the mounds had stopped. Hence the queen and king were killed after the mound was destructed (Table 1), in the manual removal of queen and king, the numbers of colonies were decreased in successive counts. Kaleab and Daniel's group in 2008 and 2010 respectively found the same result in their study to fulfill their partial requirements for BSc degree (not published). The colony size was reduced after chlorpyrifos application. There were many dead corpses inside the mound (Figure 1).

From the average counts of soldiers' workers and nymphs, the result indicates there was a significant difference between the termite castes in all treatments. Similarly there was a highly significant difference between the treatments (Table 2). Mounds treated with smoke had the highest count of colonies when compared with the other treatments. Chlorpyrifos had significantly lower number of counts (Figure 1). Two weeks after treatments, the mounds treated with chlorpyrifos showed very less activity of termites.

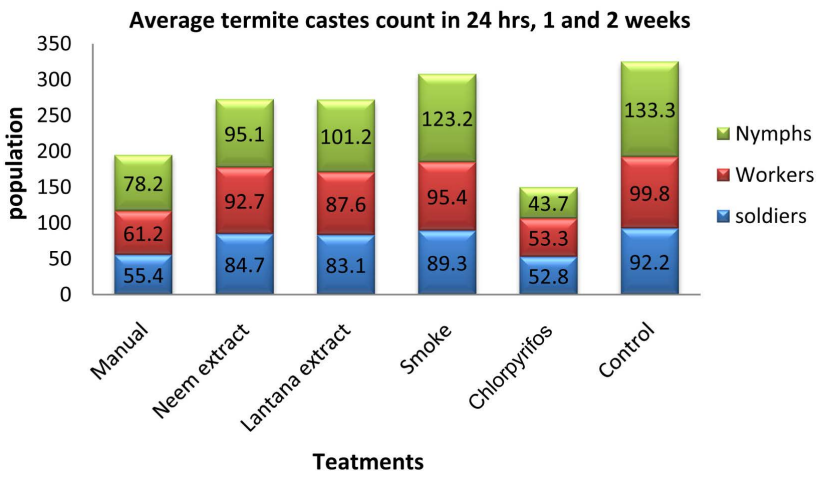

Figure 1. Mean number of workers, soldiers and nymph of termite in different treatment.

Table 1. Effect of different treatments on the average mortality of termite queen and king after two weeks.

\begin{tabular}{ccccccc}
\hline \multirow{2}{*}{ Treatment } & \multicolumn{5}{c}{ Queen and king situation in successive order } \\
\cline { 2 - 7 } & \multicolumn{2}{c}{ After 24 hrs. } & After 1 week & After 2 weeks \\
\hline Manual & Dead & Dead & Dead & Dead & Dead & Dead \\
Smoke & 1 & 1 & 1 & 1 & 1 & 1 \\
Lantana extract & 1 & 1 & 1 & 1 & 1 & 1 \\
Neem extract & 1 & 1 & 1 & 1 & 1 & 1 \\
Chlorpyrifos & Dead & Dead & Dead & Dead & Dead & Dead \\
Control & 1 & 1 & 1 & 1 & 1 & 1 \\
\hline
\end{tabular}


Table 2. ANOVA table of the mean count of soldiers, workers and nymphs.

\begin{tabular}{ccccccc}
\hline \multicolumn{1}{c}{ ANOVA } & \multicolumn{7}{c}{} & & & \\
\hline Source of Variation & SS & Df & MS & F & p-value & F crit \\
\hline Treatments & 7671.1 & 5 & 1534.22 & 15.89377 & 0.000177 & 3.325835 \\
Termite castes & 1220.343 & 2 & 610.1717 & 6.321079 & 0.016804 & 4.102821 \\
Error & 965.2967 & 10 & 96.52967 & & & \\
Total & 9856.74 & 17 & & & & \\
\hline
\end{tabular}

The manual destruction of mound in 24 hours after treatment had high population of termites with some activities such as construction of the damaged part of the mound, but after the first and second week the population decreased and the growth of the mound had stopped [20].

Treatment with smoke of wood didn't show reduction in the termite colonies (Figure 1). After smoke treatment the workers which were exposed to the burning fire and smoke died immediately but the others escape to the inner part of their mound. The next day the damaged part of the mound was found reconstructed. Complete recovery of the damaged part of the mound was re-constructed one week after treatment. Avitabile, Nimmo, Bennett and Clarke (2015) reported that the effect of fire on termite is insignificant as they hide underground inside their mounds. The queen and king were removed and killed by burning after two weeks.

Similar to the treatment with smoke, mounds treated with neem and lantana showed at first some dead termites (workers, soldiers and nymphs) but they didn't give complete control of the colony [21]. After 24 hours the termites in the treated mounds had started reconstruction of their damaged mound and they were active even though there were dead corpses inside the mound. The royal family was alive after two weeks after treatment and removed and killed by burning in order to manage the termite attack in that area (Table 1).

Termites in chlorpyrifos treated mounds did not show any sign of activity of the population. It gave complete control of the termite after one week (Figure 1). Similar studies done by Logan, Rajagopal, Wightman and Pearce (1992), Lange Wald, (2003) showed that chlorpyrifos gave good control of termites both in mound and tunnel [22] [23]. The fungal comb changed from whitish to black or brown and decayed completely with the appearance of dead termite such as soldiers, workers, nymphs, and egg. This indicates chemicals are fast in action to control the pest. Jones, 1989, found that, tunneling in soil treated with chlorpyrifos results in good control of termites and decrease grasses and other woods damaged by the pest [24].

\section{Discussion}

To select the best and easily affordable control measures of termite population, manual removal of queen, smoke, Azadractin indica and Lantana camara leaves and seed extracts and chlorpyrifos treatments were used. The treatment mounds 
were selected randomly inside HAC campus. Every treatment was replicated three times. Data was collected at $24 \mathrm{hrs}$, one and two weeks after application of the treatments. Among all chlorpyrifos and manual removal of queen controlled termite population [22]. The other treatments slightly affected the population to decrease to some extent. Later the population immediately covered the opened galleries and started their usual activities. In manual removal of queen, similar to the other treatments unlike chlorpyrifos treatment, the population started to cover the opened gallery after the queen and king were removed and burned. But they didn't continue the growth of the mound and they were dispersed due to lack of organizer queen.

The result indicates that there was a significant difference in the mean counts of nymphs, soldiers and workers among the treatments (Table 2). Highest population of termite colonies counted at mounds treated with smoke when compared to the other treatments. The insecticide had significantly lower number of population counts (Figure 1). Two weeks after treatments with the insecticide the termites' activity was very limited with very small recovery of the damaged part of the mound.

There was very high population of termite at the time where the king and queen were killed with active movements of the workers to cover the damaged part of the mound but after second week the population and their activities decreased. The result of manual removal of queen is in the line with the survey made by Malka (1972) in Nigeria [25]. He reported that by removing of the royal couples alone the termite population decreases. He also reported that when the queen was removed from the mound, the population further decline and disintegrate due to lack of regeneration or egg lying carried out by the colony. In addition to that, the colony members get disturbed and dispersed as there was no organizing that release pheromone to control the population.

Treatment with smoke did not give reduction in termite colonies (Figure 1). After the treatment was applied the workers were inactive for short time but very soon they became active and started to close the opened galleries. Complete reconstruction of the damaged gallery was done after one week from the time of application. This could be due to the smoke may not reach the inner part of the mound and the colony may hide in the fungal gargen which is found in the centre of the mound. The royal family has their own royal chamber so that this may further protect the queen and king from being completely exposed to the smoke.

Similar to the treatment with smoke, mound treated with neem and lantana resulted at first to some dead termites (soldiers, workers and nymphs) but after 24 hours all the living termites in the treated mound became active and started to construct the mound and foraging. Ahmed et al. (2016) reported that the effectiveness of neem seed extract against termite colony was not satisfactory.

Chlorpyrifos treated mounds indicated minimum activity of termite population. It gave complete control of termite after one week. A similar study done by Lange Wald (2003) tells chlopyrifos have good control of termites both in mound and tunnel. The fungal comb changed from whitish to black or brown 
and decayed completely with the appearances of dead termites such as soldiers, workers nymphs and eggs. This indicates chemicals are fast in action to control the pest [24]. He found that tunneling in the soil treated with chlorpyrifos results in good control of termites and decrease grasses and other woods damaged by the pest.

The most important termite species in that area is termitidae (mound building termite). Termitidae is the major pest of storage, wooden structural building and farm areas. Researches in Hamelmalo agricultural college indicate that the college is highly infested by termites. There is a serious problem of termite damage of grasslands, tree or bush damage and wooden structures.

Manual removal of the queen and chemical treatment (chlorpyrifos) gave complete control of the population (Figure 1). Manual removal of the queen is effective in reducing the population of termites and is friendly to the environment except it is very costly and laborious.

Neem seed kernels and leaves extract resulted in reducing the termite population even though a complete control of termite was not possible (Table 1). Therefore the farmers have to use either manual removal of the queen or repeated application of neem seed and leaves extract otherwise they have to use the chemical chlorpyrifos. Environmental pollution is also low from chemical treated mounds as the chemical is confined to that mound only. Rain water couldn't wash treated chemicals inside mounds because of the ability of mounds to block rain water unless it is completely destructed.

\section{Conclusions}

Termite mounds are treated with smoke, manual destruction of mound and killing of queen and king, leaves and seed kernel of neem, leaves and seeds of lantana and chlorpyrifos for selection of the best control measure in HAC campus. In the campus termites are the main production constraints and also affect the wooden structures of the college properties such as tables, chairs, cupboards and paper products. They can also damage crops, range land, tree seedlings and cause considerable damage to buildings and other structures such as wooden fence and woods. Gethi et al. (1995) reported that crop rotation and intercropping sometimes reduce termite populations however termites have a wide host range that can simply find other alternatives [26]. Frequent destruction of their tunnel is done in offices and classrooms to interrupt their make for foraging. The termite tunnels protect them from natural enemies and climate changes and this encourages them to forage without break. This could be the reason termites cause great losses annually. For example, in Eritrea, termites attack infrastructure of house, household furniture, trees, orchard plants, field crops, vegetable crops and pasture lands. The semi-arid savannah ecosystem of Kenya was suffering a destruction of $800-1500 \mathrm{~kg} / \mathrm{ha}$ of pasture per year. Similarly in South Africa, harvester termites were removing $60 \%$ or more of the standing grass biomass during dry years. The hidden foraging activities and environmental safety make hesitation in controlling termites outside their mounds. This in- 
itiates to find an alternative of controlling the termite population from their source mounds.

Different control measures were tested to find the best alternative. From all the control measures which were replicated three times, manual destruction of mound and killing of queen and king and chlorpyrifos were controlled the termite population. The other control measures kill some termite castes but not the royal family immediately after application although their activity resumes and the opened galleries are reconstructed later. After one week of application, complete reconstructions of the damaged part of the mounds were done. Hence the queen has high egg laying potential; the possibility of controlling the population is impossible unless the queen is dead. Two weeks after treatment the queen and king were alive in mounds treated with smoke, lantana seed and leaves and neem seed kernel and leaves that they were removed and killed later. The chlorpyrifos and manual removal of queen and king were found to be effective in controlling termite population from their mounds. Comparing the time consuming and laborious method of manual destruction to the effect of chlorpyrifos on untargeted organisms, the selection of the best one from these two control measures is narrow as chlorpyrifos is applied in a confined mound and the mounds water resistant nature. But the chance of poisoning untargeted organisms is not zero as wild animals make their shelter in termite mounds.

\section{Acknowledgements}

The authors acknowledge all the members of open journal of ecology publishers for covering $70 \%$ of the publication fee, the reviewers and audience.

\section{Conflicts of Interest}

The authors declare no conflicts of interest regarding the publication of this paper.

\section{References}

[1] Harris, W.V. (1961) Termites: Their Recognition and Control. Longmans, London.

[2] Hill, D.S. (1990) Pests of Stored Products and Their Control. Belhaven Press, London, 53-59.

[3] Grzimek, B. (2003) Animal Life Encyclopedia. Insect, 2, 130-155.

[4] Maniania, N.K., Ekesi, S. and Songa, J.M. (2002) Managing Termites in Maize with the Entomopathogenic Fungus Metarhizium anisopliae. Insect Science and Its Application, 22, 41-46. https://doi.org/10.1017/S1742758400015046

[5] Abdurahman, A. (1990) Foraging Activity and Control of Termites in Western Ethiopia. University of London, London.

[6] Eden, T. (1965) Tea. 2nd Edition, Longmans, Green and Co., London, 132-133.

[7] Lapage, M.G. (1981) The Impact of Foraging Populations of Macroterms michaelseni (Sjostadt) (Isoptera: Macrotermitinae) on Semi-Arid Ecosystem (kajiads Kenya) I-Foraging Activity and Factors Determining It. Insects Sociaux, 28, 297-308. https://doi.org/10.1007/BF02223630 
[8] Avitabile, S.C., Nimmo, D.G., Bennett, A.F. and Clarke, M.F. (2015) Termites Are Resistant to the Effects of Fire at Multiple Spatial Scales. PLOS ONE, 10, e0140114. https://doi.org/10.1371/journal.pone.0140114

[9] Donald, M.C. and Harness, (1968) Aflatoxin in the Groundnut Crop at Harvest in Northern Nigeria. Tropical Science, 8, 148-161.

[10] Blackburn, F. (1984) Sugarcane. Longman, New York.

[11] Johnson, R.A. and Gumel, M.H. (1991) Termites Damage and Crop Loss Studies in Nigeria-The Incidence of Termites Scarified Groundnut Pods and Resulting Kernel Contamination in Field and Market Studies. Tropical Pest Management, 27, 343-350.

[12] Maayiem, D., Nuoleyeng, B.B. and Oscar, A.I. (2012) Indigenous Knowledge of Termite Control: A Case Study of Five Farming Communities in Gushegu District of Northern Ghana. Journal of Entomology and Nematology, 4, 58-64.

[13] Coulson, N.R. and Witter, J.A. (1984) Forest Entomology, Ecology and Management USA. Wiley Interscience Publication, Hoboken.

[14] Singh, S.R. (1990) Insect Pest of Tropical Food Legumes. John Wiley and Sons, New York, 249-260.

[15] Lapage, M.G. (1981) The Impact of Foraging Populations of Macroterms michaelseni (sjostadt) Isoptera: Macrotermitinae in Semi-Arid Ecosystem (Kajiads Kenya) II-Food Gathered in Comparison in with Large Herbivores. Insects Sociaux, 28, 309-379. https://doi.org/10.1007/BF02224188

[16] Coaton, W.G.H. (1958)The Hodotermitide Harvester Termites of South Africa, Union of Africa. Department of Agriculture, Entomological Series No. 43, Bull 375.

[17] Sands, W.A. (1977) The Role of Termites in Tropical Agriculture. Outlook on Agriculture, 9, 136-143. https://doi.org/10.1177/003072707700900307

[18] Amburgey, T.L. and Beal, R.H. (1977) White Rot Inhibits Termites Attack. Sociobiology, 3, 35-38.

[19] Smith, J.L. and Rust, M.K. (1990) Tunneling Response and d Mortality of the Western Subterranean Termite, Reticuliterms Hesperus (Isopteran: Rhinotermitidae) to Soil Treated with Insecticide. Entomology, 83, 1395-1401. https://doi.org/10.1093/jee/83.4.1395

[20] Sindhu, S.S., Rakshiya, Y.S. and Verma, M.K. (2011) Biological Control of Termites by Antagonistic Soil Microorganisms. In: Singh, A., Parmar, N. and Kuhad, R., Eds., Bioaugmentation, Biostimulation and Biocontrol, Vol. 108, Springer, Berlin, Heidelberg, 261-309. https://doi.org/10.1007/978-3-642-19769-7_12

[21] Ahmed, N., Huma, Z., Haq, M.U., Rehman, S., Ullah, M. and Ahmed, S. (2016) Effect of Different Plant Extracts on Termite Species (Heterotermis indicola). Journal of Bio-Resource Management, 3, 9-16. https://doi.org/10.35691/JBM.6102.0049

[22] Logan, J.W.M., Rajagopal, D., Wightman, J.A. and Pearce, M.J. (1992) Control of Termites and Other Soil Pests of Groundnuts with Special Reference to Controlled Release Formulations of Non-Persistent Insecticides in India and Sudan. Bulletin of Entomological Research, 82, 57-66. https://doi.org/10.1017/S000748530005149X

[23] Neuenschwander, P., Borgemeister, C. and Langewald, J. (2003) Biological Control in JPM Systems in Africa. Centre for Agriculture and Bioscience International, London.

[24] Jhone, S.C. (1989) How Toxic and Repellants Soil Insecticide to Subterranean Termites Pest Management, 8, 16-19.

[25] Malka, S.L.O. (1972) Some Measures Applied in the Control of Termites in Parts of Nigeria. Nigerian Entomologists Magazine, 2,137-141. 
[26] Gethi, M., Gitonga, W. and Ochiel, G.R.S. (1995) Termite Damage and Control Options in Eastern Kenya. Proceedings of 2 nd Regional Workshop on Termite Research and Control, Nairobi, 9 March 1995, 7-9.

\section{Abbreviations and Acronyms}

$$
\begin{aligned}
& \text { HAC = Hamelmalo Agricultural College } \\
& \mathrm{L}=\text { Liter } \\
& \mathrm{M}=\text { meter } \\
& \mathrm{Cm}=\text { centimeter } \\
& \mathrm{Kg}=\text { kilo gram } \\
& \mathrm{Ha}=\text { hectare } \\
& { }^{\circ} \mathrm{C}=\text { degree celsius } \\
& \mathrm{Hrs}=\text { hours } \\
& \text { ANOVA = analysis of variance } \\
& \mathrm{SS}=\text { sum of squares } \\
& \text { Df = degrees of freedom } \\
& \text { MS = mean squares } \\
& \mathrm{F}=\text { variation between sample means } \\
& \text { p-value = probability value } \\
& \mathrm{F} \text { crit = F critical value } \\
& \text { et al. = and others }
\end{aligned}
$$

